\title{
Mito MUSICAdO E MÚSICA MÍTICA: UMA PERSPECTIVA ANTROPOLÓGICA DA OBRA DE RICHARD WAGNER
}

\section{Maria Raquel da Cruz Duran ${ }^{1}$}

\begin{abstract}
Resumo
Propõe-se um estudo sobre as relações entre música, sociedade e mito na obra de Richard Wagner, destacando a importância do mito e da música como linguagens de interpretação da cultura e a difusão que a obra wagneriana proporcionou à mitologia germânica na cultura ocidental. Destarte, menciona o antropólogo Anthony Seeger, interpretamos a música como um elemento-chave do processo de construção do mundo social e conceptual, sendo o estudo da performance, uma análise figurativa da vida social. Embora coexistam diversas ideologias em cada mito, alvitra-se uma discussão a respeito dos subsídios que a ópera Tristão e Isolda, em especial, conferiu à ideia de mito, inserindo-se aqui valores percebidos tanto na sociedade do século XIX quanto na atual.
\end{abstract}

Palavras-chave: Antropologia sonora. Mito. Richard Wagner. Sociedade.

\footnotetext{
${ }^{1}$ Mestranda em Ciência, Tecnologia e Sociedade pela Universidade Federal de São Carlos. End. eletrônico: clavedera@yahoo.com.br
} 


\title{
MUSICAL MYTH AND MYTHICAL MUSIC: AN ANTHROPOLOGICAL PERSPECTIVE OF RICHARD WAGNER'S WORK
}

\begin{abstract}
A study of the relationships between music, society and myth in the work of Richard Wagner is proposed; highlighting the importance of myth and music as language for culture interpretation and dissemination of Germanic mythology in Western culture provided by Wagner's works. Thus mentioning anthropologist Anthony Seeger, we interpret music as a key element in the process of building social and conceptual world, being the study of the performance, a figurative analysis of social life. Although several ideologies coexist in each myth, a discussion is proposed regarding the subsidies that the opera Tristan and Isolde, in particular, granted to the idea of myth, introducing values that could be perceived both in XIX century and today's society.
\end{abstract}

Keywords: Sound Anthropology. Myth. Richard Wagner. Society

\section{Mito MUSICAdO E MÚSICA MÍTICA: UMA INTRODUÇÃO AO TEMA}

$\mathrm{D}$ uas esferas que pareciam viver estranhas e indiferentes por causa da tradicional sociedade oitocentista viram-se unidas na Nova Era forjada por Richard Wagner ${ }^{2}$ que, ao criar o drama musical, 'território intermediário entre o mito e a música' (DIAS, 2005, p. 99), devolveu ao mito a característica de imagem do mundo.

Wagner abordava no mito, a coletividade, o Dionísio comum em cada indivíduo, e, na música, a individualidade apolínea, uma designação que valorizava o olhar sensível de cada um. No entanto, ao entrelaçar tais vetores, Wagner produzia um misto de sensações, à sua arte dava o nome de Obra de Arte Total: caracterizada por esta textura diferenciada, uma imagem que gera música, uma arte que transmitiria ao homem a essência das coisas, sem intermediações.

A composição wagneriana se enquadra na escola romântica, cujos representantes, além de Wagner eram: Ernest Hoffmann, Paganini e Franz

\footnotetext{
${ }^{2}$ Richard Wagner nasceu em Leipzig em 22 de maio de 1813 e morreu em Veneza em 13 de fevereiro de 1883. 0 músico é mundialmente conhecido pela autoria de óperas como: Parsifal, a tetralogia de O Anel dos Nibelungos, Lohengrin, Tristão e Isolda, Os Mestres Cantores, entre outras.
} 
Schubert. 0 crescente cromatismo, a tendência para formas mais livres, 0 nacionalismo, o uso de material folclórico, a preferência pelo pitoresco e 0 gosto pelo fantástico, além de uma aversão a tudo que fosse rotineiro, realista, burguês, são algumas das características que diferenciam os músicos da escola romântica de outros músicos, como por exemplo, da escola barroca ou da escola classicista.

Advindo da herança sinfônica de Beethoven, o músico eleva a orquestra ao papel de protagonista do drama musical, num aprofundamento do mesmo, onde tudo deve se enquadrar à execução musical. Contemporâneo da segunda metade do século XIX, em plena idade industrial, Wagner exterioriza o desejo crescente da burguesia de evasão para um mundo melhor, tornando sua influência avassaladora.

Neste ensejo, é introduzida por Richard Wagner uma série de mudanças físico-espaciais, que consolidaram esse pensamento inovador e recente, é claro, reavivando o fervor das discussões musicais da época:

A parte externa do prédio era nua, quase desoladora, porque Wagner desejava focalizar toda a atenção na arte que se realizava no interior. Este era espantoso por duas razões. Em primeiro lugar, todas as cadeiras estavam arrumadas à maneira de um anfiteatro; cada membro do auditório tinha uma visão do palco sem qualquer obstáculo; não tinha, porém, uma visão clara dos demais membros da platéia, pois esta não era a razão pela qual deveriam, segundo Wagner, ir ao teatro. 0 palco era tudo.

Num arroubo ainda mais radical, Wagner escondeu a orquestra da vista da platéia, cobrindo o poço da orquestra com uma tampa de couro e madeira. Desse modo, a música era ouvida, mas nunca era vista se produzindo. Mais tarde, Wagner constrói um segundo arco de proscênio, acima das extremidades do poço da orquestra, além do arco sobre o palco (SENNETT, 1988, p. 258).

Todavia, as inovações deste autor não cessam em condições físicas de execução musical e teatral. Richard Wagner foi o responsável pela difusão do uso dos leitmotiven, ou seja, a ligação do personagem a uma música para que ao longo da ópera, quando o personagem fosse citado, sua música tema enfatizasse ou fizesse com que o público reconhecesse o referido personagem e rememorasse sua trajetória naquela história. Claude Lévi-Strauss comenta a utilização do leitmotiv ora como resgate constante da memória de uma parte essencial do mito contado - o mitema - pelo público, ora como reafirmação do momento atual da encenação: 
Wagner não só construiu óperas sobre mitos, mas deles propõe um recorte que o emprego do leitmotive torna explícito: 0 leitmotiv prefigura o mitema. Além do mais, o contraponto, dos leitmotiven e do poema realiza uma espécie de análise estrutural, já que se superpõem, por deslizamentos ou deslocamentos, momentos de intriga que, caso contrário, só se sucederam no tempo. Ora o leitmotiv, musical, e o poema, literário, coincidem; ora o leitmotiv faz retornar um episódio relacionado estruturalmente com o episódio que assistimos, seja por analogia ou por contraste" (LÉVI-STRAUSS, 2005, p. 247).

Considerando esta premissa da figura e da obra de Richard Wagner, analisar na ópera Tristão e Isolda - considerada de importância central na obra do músico pelos críticos de música clássica e de Wagner - a difusão de algumas das performances sociais do século de Wagner, sendo central refletirmos o papel da mitologia dentro das óperas wagnerianas é o objetivo indicado neste artigo, pois, para além de integrar a apresentação do tema, é fundamento de nossa justificativa.

Na reflexão das relações entre mito, música e sociedade, propomos o estudo tanto da ópera quanto do mito na construção da etnografia ritual do drama social, tal como observamos em Mello (2005) em que as três afirmações cantadas nas atividades musicais desenvolvidas entre as mulheres Wauja - a saber, "não se pode desejar aquilo que não se pode ter", "o ciúme, devidamente controlado, é bom para a sociedade" e "a música do ritual de yamurikama, cantada por mulheres, é música de kawoka” - representam a forma como são moldadas as relações entre as pessoas no convívio social e na performance mítica do rito (COELHO, 2007).

Numa visão universal, música é cultura, é arte, e, portanto, é manifestação de crenças, de identidades ou, como diria Tiago de Oliveira Pinto, é um meio de interação social, é um comportamento decodificado em sons que transmite uma comunicação entre indivíduo e grupo (PINTO, 2001, p. 3). Se o mito é a simbolização visível da música, é linguagem absoluta, é a representação do pensamento da sociedade, sendo entendido como cultura, então podemos, em resumo, dizer que "A música expõe ao indivíduo seu enraizamento fisiológico, a mitologia faz o mesmo com o seu enraizamento social. Uma nos pega pelas entranhas, a outra, digamos assim, "pelo grupo' " (LEVI-STRAUSS, 2004, p. 48). Assim como exteriorizou o canto entre os Suyá, observados por Anthony Seeger em sua interpretação, a relação do indivíduo com a sociedade:

Voltando a pergunta Por que os Suyá cantam?, o autor afirma que cantar "era uma maneira essencial de articular as experiências de suas vidas com 0 processo de sua sociedade" (p.128). A noção de kin (euforia) surge como 
elemento central em uma sociedade que, como os demais grupos Ge, não faz uso de alucinógenos ou bebidas alcoólicas nos ritos. Assim, o canto e a dança cumprem também um papel fisiológico na própria constituição dos estados psíquicos, atualizando a experiência dos eventos míticos (COELHO, 2007,p. 3).

A ideia de que a mitologia compõe uma característica de imagem do mundo, de uma linguagem interpretativa da cultura - na noção definida por Lévi-Strauss (1967) - sendo, portanto, expressão de sentimentos fundamentais de uma sociedade compartilhados pela humanidade - obtendo um espaço mais significativo do que aquele ocupado pelo conto de fadas ou ficção, ou seja, elevado à categoria de parte do pensamento de uma sociedade e de uma época determinadas, nos introduz o pensamento de que,

Em outras palavras, o que a música e a mitologia acionam naqueles que as escutam são estruturas mentais comuns. 0 ponto de vista que adotamos implica, conseqüentemente, o recurso a essas estruturas gerais repudiadas pela doutrina serial, cuja própria realidade ela contesta. Por outro lado, essas estruturas só podem ser chamadas de gerais se lhes for reconhecido um fundamento objetivo para aquém da consciência e do pensamento, ao passo que a música serial se quer espírito e afirmação de sua própria liberdade. [...] Contudo, quando se escolhe, como fizemos neste livro, o olhar do mito em direção a música, e não em direção a linguagem, como tentamos fazer em obras anteriores, o lugar privilegiado que cabe à música aparece com mais evidência (LEVI-STRAUSS, 2004, p. 47).

Nesta perspectiva antropológica de análise da música percebemos que, ao tratarmos a música como uma forma de comunicação com a mitologia e a sociedade, o olhar da música em direção ao mito, compreendemos aspectos sociais/ ideológicos vinculados à atividade musical que Wagner propôs, passando a música a agir como uma solidificadora de mitologias então difundidas, compartilhando da ideia de música como um tipo de ação social:

[...] a música não pode mudar a sociedade, tal qual a tecnologia ou a política, mas pode confirmar situação pré-existentes. Não gera pensamentos, mas faz as pessoas mais conscientes de sentimentos que elas experimentaram, ao reforçar, alargar ou expandir suas consciências. A música seria um tipo especial de ação social, não somente reflexiva, mas também geradora. Música, para Blacking, é produto da ação humana e modo de pensamento gerador de ação humana. A relação entre música e sociedade não é direta - a música não muda a sociedade - mas "cognitiva": o fazer musical pode ser ferramenta 
indispensável para a transformação da consciência, um primeiro passo para a transformação das formas sociais (HIKIJI, 2006, p. 64).

Acredita-se que algumas das óperas wagnerianas - entre elas Tristão $e$ Isolda - direcionaram o significado dos mitos utilizados em suas encenações para a afirmação de um arcabouço teórico já existente, embora não se mostrasse totalmente visível. Wagner retira do mito os comportamentos espiritualmente indignos dos protagonistas, para produzir um contexto propício à sacralização do mundo material. Os sacrifícios do herói mitológico são sempre marcados pela recompensa que pretende alcançar como resultado - quanto maior a recompensa maior o preço a ser pago.

Como já afirmou Marshall Sahlins (2004a, p. 23) "um povo que concebe a vida exclusivamente como busca da felicidade só pode ser cronicamente infeliz". 0 herói dramático de Wagner carrega o fardo de pagar por um erro que não cometeu ou apenas, pagar o preço por amar alguém inacessível, por ter um amor proibido, por desejar a felicidade. Sahlins comenta tal redução das propriedades sociais em valores de mercado - ou seja, ter que "pagar" pelo que fez ou quer - são representações da dominação que o capitalismo nos impõe. Na ópera em que o mito de Tristão é colocado, o homem tem como princípio sofredor ter cometido o pecado de afrontar a Deus e a natureza, tal prática é comum em mitologias, como explicita Sahlins (2004c, p. 565).

Disposição da cena teatral, texto mitológico, música arrebatadora, tudo construiu esse fenômeno comportamental que atingiu principalmente a burguesia - elite freqüentadora dos salões de ópera mais respeitados da Europa - onde Richard Wagner era rei. Atento para a importância da música como difusora desse mito e conseqüentemente de suas ideologias: música, cuja percepção foi tão bem posta a ponto de gerar a "febre Wagner" na Europa, a imensa exaltação de sua obra no mundo.

\section{REFERÊNCIAS}

AMARAL, Adriana; NATAL, Geórgia; \& VIANA, Luciana. Netnografia como aporte metodológico da pesquisa em comunicação digital. Famecos/PUC-RS, Comunicação Cibernética, vol. 1, n. 20, Porto Alegre, 2008.

BARENBOIM, Daniel \& SAID, Edward. Paralelos e paradoxos: reflexões sobre música e sociedade. São Paulo: Companhia das Letras, 2003. 
BLACKING, John. How musical is man? Seattle: University of Washington Press, 1973.

BLACKING, John. Music, culture and experience. Selected Papers. Chicago: University of Chicago Press, 1995.

BURNETT, Henry. 0 Beethoven-Schrift: Richard Wagner teórico. Trans/Form/ Ação, vol. 32, n. 1. Marília, 2009.

CAZNOK, Yara Borges \& NAFFAH NETO, Alfredo. Ouvir Wagner: ecos nietzschianos. São Paulo: Musa Editora, 2000.

CAZNOK, Yara Borges. Música: entre o audível e o visível. São Paulo: Unesp, 2003. COELHO, Luís Fernando Hering. A nova edição de Why Suyá Sing, de Anthony Seeger, e alguns estudos recentes sobre música indígena nas terras baixas da América do Sul. Mana: Estudos de Antropologia Social, vol. 13, n. 1, Rio de Janeiro, 2007.

COHN, Clarice; VIEIRA, José Glebson; LIMA, Leandro Mahalem de; SZTUTMAN, Renato \& HIKIJI, Rose Satiko Gitirana. Por que canta Anthony Seeger? Revista de Antropologia, vol. 50, n. 1, São Paulo, 2007.

FELD, Steven. Sound and sentiment: Birds, Weeping, Poetics and Song in Kaluli Expression. Philadelphia: University of Pennsylvania Press, 1982.

HIKIJI, Rose Satiko Gitirana. A música e o risco: etnografia da performance de crianças e jovens. São Paulo: Edusp, 2006.

LANZA, Diego. A dramatização do mito. KRITERION: Revista de Filosofia, vol. 44, n. 107, Belo Horizonte, 2003.

LÉVI-STRAUSS, Claude. Olhar, escutar, ler. São Paulo: Companhia das Letras, 1997.

. A estrutura dos mitos. In: Antropologia estrutural. Rio de Janeiro: Tempo Brasileiro, 1967.

. De perto e de longe. Entrevistas a Didier Eribon. São Paulo: Cosac Naify, 2005.

. Mitológicas I: 0 cru e o cozido. São Paulo: Cosac Naify, 2004

MELLO, Maria Ignez C. Música e mito entre os Wauja do Alto Xingu. Dissertação de Mestrado, Antropologia Social, Universidade Federal de Santa Catarina, 1999. 
MENEZES BASTOS, Rafael José de. Musicológica Kamayurá: para uma antropologia da comunicação no Alto-Xingu. Florianópolis: Editora da UFSC, 1999.

MERRIAM, Alan P. The anthropology of music. Evanston: Northwestern University Press, 1964.

NATTIEZ, Jean-Jacques. Music and discourse. Princeton: Princeton University Press, 1990.

NEUMAN, Ernest. História das grandes óperas e de seus compositores. vol. I. Rio de Janeiro: Globo, 1949.

ORTEGA y GASSET, José. A desumanização da arte. São Paulo: Cortez, 2003.

PINTO, Tiago de Oliveira. Som e música: questões de uma antropologia sonora. Revista de Antropologia, vol. 44, São Paulo, 2001.

SAHLINS, Marshall Esperando Foucault, ainda. São Paulo: Cosac \& Naify, $2004 a$. . Cosmologias do capitalismo: o setor trans-pacífico do "sistema mundial".

In: Cultura na Prática. Rio de Janeiro: Editora UFRJ, $2004 b$. . A tristeza da doçura, ou a antropologia nativa da cosmologia ocidental.

In: Cultura na prática. Rio de Janeiro: UFRJ, 2004c.

SCHNEIDER, Marcel. Wagner. São Paulo: Martins Fontes, 1991.

SEEGER, Anthony. Why Suyá sing: A musical anthropology of an amazonian people. Cambridge: Cambridge University Press, 1987.

SENNETT, Richard. O declínio do homem público: as tiranias da intimidade. São Paulo: Companhia das Letras, 1988. 